\title{
Performance Evaluation Research of Ecological Civilization Policy Based on Stochastic Frontier Analysis and Artificial Neural Networks Model
}

\author{
Yuting Xuan* \\ School of Public Affairs, University of Science and Technology of China 96 Jinzhai Road,Hefei \\ 230026, the People's Republic of China \\ * E-mail of the corresponding author: xuanyt@,mail.ustc.edu.cn
}

DOI: $10.7176 / J L P G / 77-139$

\begin{abstract}
Ecological civilization is a new form of human civilization that solves the contradiction between development and environment. Because the ecological civilization policy system has is complex and nonlinear, this paper combines artificial neural network technology with the Stochastic Frontier Analysis(SFA) method and proposes the hybrid SFA-Artificial Neural Network (SFANN) model to estimate the impact of ecological civilization policy on economic development. The model uses regional eco-efficiency evaluated by SFA as one of the inputs for the neural network; the neural network integrates the total input and output results to provide a quantitative estimate of the ecological civilization policy in different provincial regions from 2003-2016. By training and examining the evaluation results with the SFANN model, this paper tries to predict the impact of 13th Five-Year Total Emission Reduction Policy on economic development. The empirical research results and suggestions can improve the ecological civilization policy performance by negative feedback mechanisms.
\end{abstract}

Keywords: Eco-efficiency; Ecological Civilization Policy; Performance Evaluation; Stochastic Frontier Analysis; Artificial Neural Network

\section{Introduction}

In the age of industrial civilization, the unlimited extraction of natural resources and unrestrained discharge of contaminants led to many serious consequences, such as energy exhaustion, resource shortages, environmental pollution, and ecological imbalance. Thus, natural disasters and ecological crises crop up frequently. Such a phenomenon is especially serious in developing countries such as China. Although China's reform and opening up resulted in the impressive "China Speed", the extensive style of economic growth nevertheless created many environmental problems, including soil desertification, water quality degradation, and air pollution. These environmental problems not only significantly depress people's heath and quality of life but also corrode economic milestones. To balance the contradiction between economic development and environmental quality, the Chinese Government proposed a new form of human civilization based on the theory and practice of sustainable development in developed western countries called ecological civilization and published a series of policies(Ji-Hong, 2007).

Ecological civilization policy is a new form of ecological policy that exists only in China. Based on foreign environmental policy, ecological civilization policy in China is defined as all the normalization, straitjacket, and guidance rules for supporting, promoting, and ensuring the realization of ecological civilization. This policy consists of enforcement measures, such as legislation, and non-enforcement measures, such as public participation(Xiuyu Zhang, Li, Shi, \& Yang, 2015). The performance of ecological civilization policy refers to the environmental reception and achievement arising from the implementation of ecological civilization policy. It describes not only the effect of the ecological civilization construction on the local economic environment but also the cost of decreasing resource utilization and environmental contamination. It thus reflects the concept of ecological efficiency(Aibao, 2010). Although the policy in general does not have an immediate effect, the feasibility and effectiveness of one policy can be predicted through the use of scientific evaluation tools and specific mathematical models. Thus, it is possible to regulate the policy by observing the difference between the predicted result and the expected. As a result, policy performance evaluation is the ending as well as the starting point of the policy(Cao \& Cao, 2010).

The evaluation index system for foreign sustainable development includes:

1. A causation framework model, such as the Pressures-State-Responses Model proposed by the Organisation for Economic Co-operation and Development (OECD) (OECD, 1998) (Figure 1), the Drivers-Pressures-State- 
Impact-Responses Model proposed by the Commission on Sustainable Development (CSD)(WBCSD, 1996), , or the Drivers-Pressures-State-Impact-Responses model proposed by the European Environment Agency (EEA)(Maxim, Spangenberg, \& O'Connor, 2009). (Figure 2). These models are intuitive and have a relatively precise description of the casual link between humans and the environment, but it is impossible to simulate a complex nonlinear system such as a policy system.

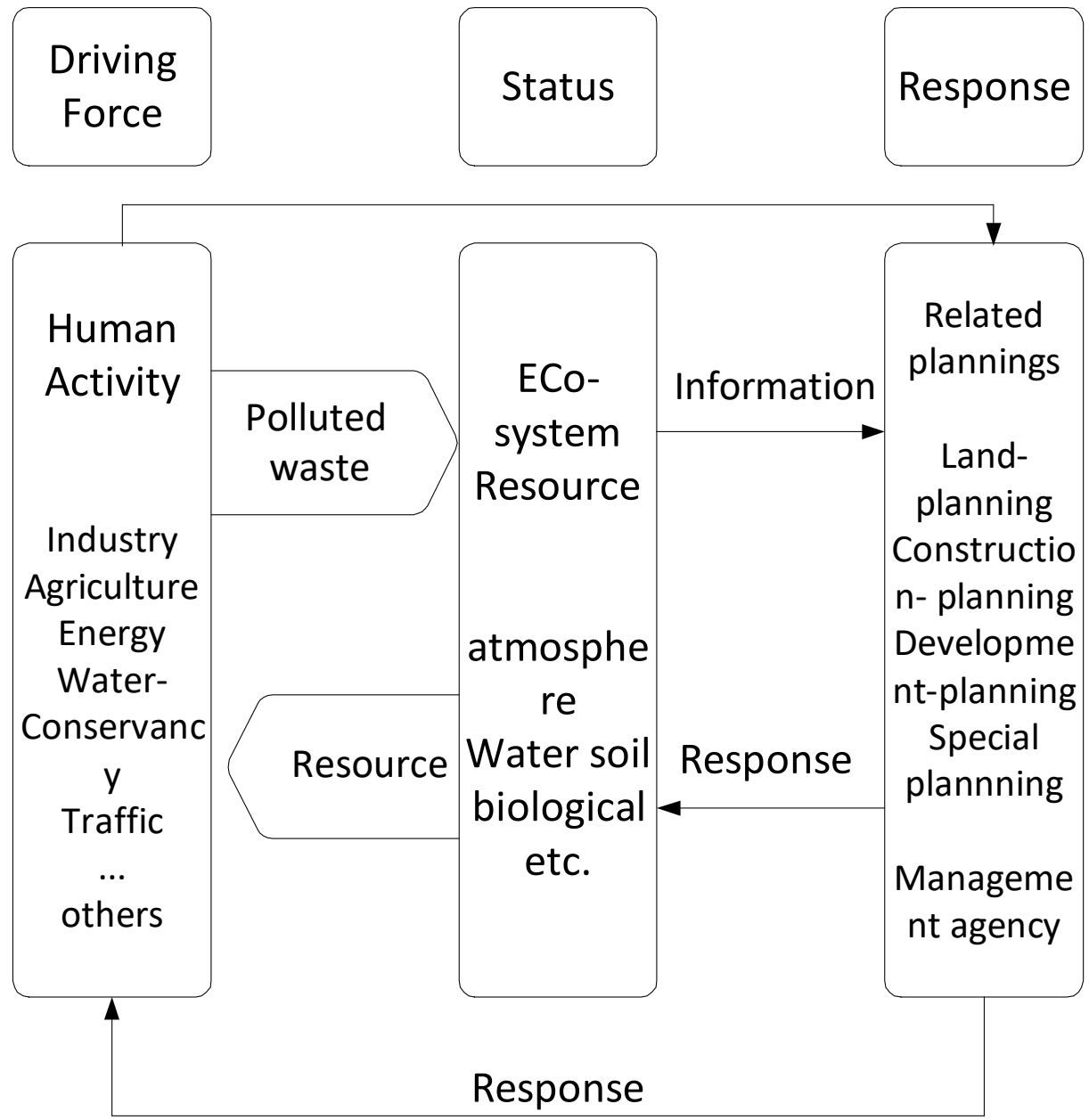

Figure 1. The Pressures-State-Responses model

2. A theme framework model, such as the Environmental Performance Index proposed by Yale University in collaboration with Columbia University (Vörösmarty et al., 2010). The indicators are selected according to the objectives of the environmental policy. Under each environmental theme, there are several subtopics with parallel relationships, and each subtopic is the basis for selecting the indicators at the next level. This model could stress the policy focus and effectively avoid the repeat set problems, but it adopts a simple additive algorithm in describing the coupling relation between subjects of the same level.

3. An Input-Output-Outcome-Impact framework model, such as the Ecological Footprint Indicators proposed by Canadian eco-economists(van den Bergh \& Verbruggen, 1999). This model is a kind of economics direction model. It selects indicators from the four aspects of input, output, outcome, and impact according to the regulation of energy and material flow and reflecting the relationship between economic input and output. This model depicts the relation between economics and the environment directly, but it is unable to quantify the evaluation system thoroughly. 


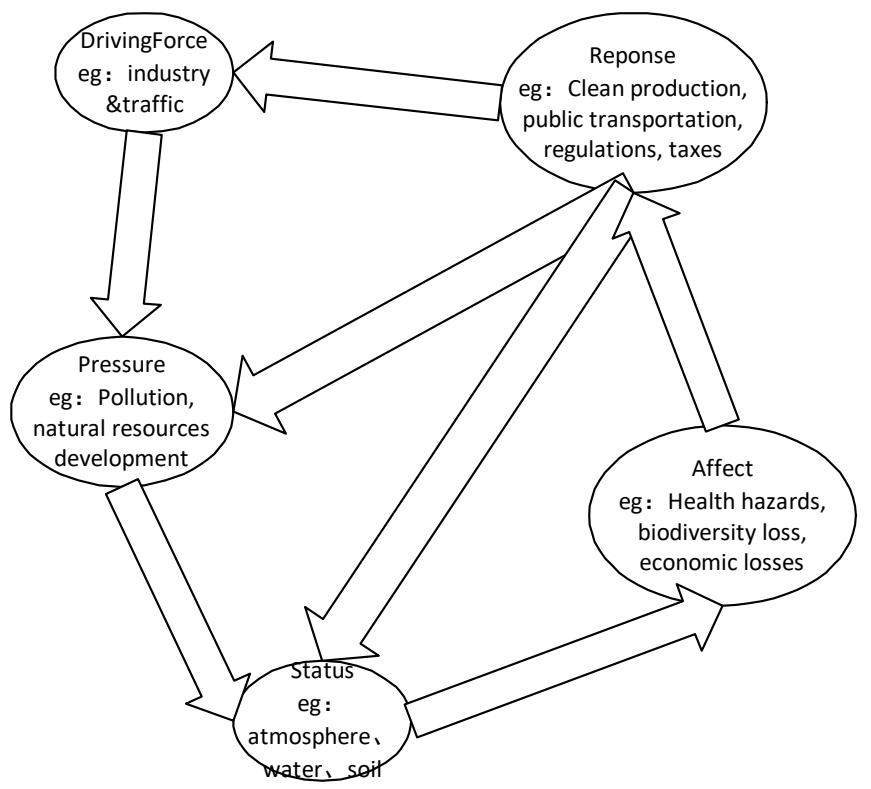

Figure 2. The Drivers-Pressures-State-Impact-Responses model

For the ecological civilization policy proposed by the Chinese government, the evaluation index system is just beginning to develop. The provincial Ecological Civilization Index presented by the Ecological Civilization Research Centre at Beijing Forestry University(Liu, 2010) and the provincial Green Development Index advanced by the Ministry of Ecology and Environment of the People's Republic of China (Li-Yang, Zheng, \& Wang, 2013) are both constructed by the theme framework model. Regardless of the evaluation index, the Analytic Hierarchy Process (AHP) algorithm(Gass \& Vargas, 2017), a kind of linear evaluation method, is widely used in the performance evaluation of ecological civilization policy at present.

In this paper, we propose a new ecological civilization policy evaluation method by using the Input-OutputOutcome-Impact framework model based on the principle of economics. To our knowledge, such a quantified economic model has never been reported. In addition, when constructing the evaluation algorithm, the artificial neural network model was adopted to enable the algorithm to simulate the characters of the complex nonlinear system. In comparison with the currently used linear evaluation method, our method has significant advantages in predicting the impact of ecological civilization policies on the economy.

\section{Methodology}

\subsection{The impact of ecological civilization policy on the economy}

The viability of ecological civilization policy is dominated by the technical and economic feasibility. It is easy to estimate the technical practicability; however, the relation between economics and the environment is complex, and it is very difficult to strike a balance between these two. The Chinese government is undergoing a continuous deepening of understanding regarding the relation between economics and the environment (Figure 3). At the beginning of the period of reform and opening up, economics dominated and environmental protection was ignored. Better invaluable assets than clear water and lush mountains. With the idea of sustainable development gradually taking root, the government has published numerous policies to protect the environment. However, as economic development and environmental protection are simply considered to be independent, the effect of these policies on economic development is studied exclusively when making these policies. Clear water, lush mountains and invaluable assets are all considered as well. The ecological civilization policy was proposed at the 17th conference of the CCP and embedded in the five-pronged approach to modernize socialism for China at the 18th conference of the CCP. Included in the idea of ecological civilization is the idea that economic development and environmental economics affect the protection of the environment, and a beautiful environment promotes economic development. Clear water and lush mountains are invaluable assets (Xiao Zhang \& Yue, 2017). 


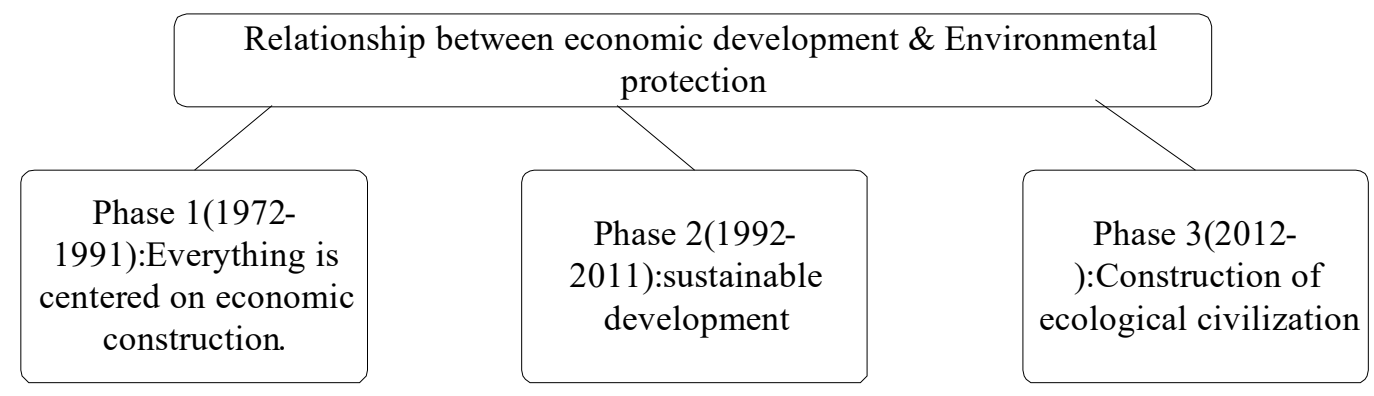

Figure 3. Relationship between economic development \& environmental protection

Specifically, ecological civilization policy boosts economic growth from two aspects. One is to improve the ecological efficiency, which is the ratio of the value of economic activity to that of consumed resources and the environmental load. As a result, higher ecological efficiency corresponds to more product output and less unexpected output under the same productive investment and environmental cost. The other result is the control of the total amount of environmental cost and pollution discharge. These two aspects are related. For example, controlling the total amount directly limits the amount of input in the short term; however, in the long run, it also forces the economy to create innovative technology to boost efficiency.

\subsection{Application of Artificial Neural Network in Performance Evaluation of Ecological Civilization Policy}

The ecological civilization policy system is a complex system the includes economics, society, and the environment. It has characteristics including obvious nonlinearity and uncertainty. Due to the lack of a physical prototype of abstract systems such as the social system, the economic system, and the ecological system, the relevant model is based upon a logical deduction. As the linear model arising from conventional econometrics is inadequate to estimate a complex system, the artificial neural network method is introduced to the new method of evaluating the performance of ecological civilization policy.

The artificial neural network has advantages such as a strong adaptive capability, a self-learning capability, and a fault-tolerant capability (Xiao, Ye, Zhong, \& Sun, 2009). Its multi-input multi-output structure is suitable for non-massive parallel calculation. In 2006, Hinto et al. proposed deep learning, which significantly improves the calculation capacity of an artificial neural network by a relatively simple violence calculation (Y. Zhang \& Wu, 2009). Today, the process of using a neural network to predict the economy is as follows: network topological structure design, data sample acquisition, input and output data pretreatment, network training, and examination and prediction of network prediction capability(Sc, Cowan, \& Grant, 1991).

To precisely predict and evaluate the total effect of the ecological civilization policy on economics, the environment, and society, the model should be able to simulate the multi-effect of the policy. In this paper, we use a combined forecasting method comprising the following four steps.

(1) Choosing the ecological efficiency index and providing the static, quantitative ecological efficiency of the local area.

(2) Using static ecological efficiency as one of the inputs of the neural network, which integrates the total input and output results, constructing a hybrid SFA-Artificial Neural Network model for evaluating the performance of ecological civilization policy.

(3) Training the neural network and examining the result using another sample data.

(4) Using the SFANN model to predict the effect of ecological civilization policy on economics.

\section{Evaluation of regional eco-efficiency using the SFA model}

\subsection{SFA model with the impact of environmental capacity}

Ecological civilization policy promotes economic development by boosting ecological efficiency. In this paper, the local ecological efficiency was predicted using the SFA model with environmental capacity(Reinhard, Knox Lovell, \& Thijssen, 2000).

The SFA model is one of parametric approaches for evaluating efficiency. It defines a priori except for a finite set of unknown parameters that are estimated from data. The parameters may for example refer to the relative importance of different cost drivers or to the parameters in the possibly random noise and efficiency 
distributions(Battese \& J. Coelli, 1988).

A stochastic production frontier is defined by

$$
\operatorname{lny}_{i}=\beta_{0}+\sum_{1}^{k} \beta_{k} \ln x_{k i}+\ln \xi_{i}+v_{i}-u_{i}
$$

where for all farms indexed with a subscript $\mathrm{i}$;

yi denotes the production level;

$\mathrm{x}_{\mathrm{i}}$ is a vector of normal inputs (such as $\mathrm{x}_{1 \mathrm{i}}$ is the labour, $\mathrm{x}_{2 \mathrm{i}}$ the capital, $\mathrm{x}_{3 \mathrm{i}}$ the variable inputs, $\mathrm{x}_{4 \mathrm{i}}$ a vector of year dummies reflecting technological and regulatory developments);

$\beta$ and $\xi$ are parameters to be estimated;

$\mathrm{V}_{\mathrm{i}}$ is a symmetric random error term independently and identically distributed as $\mathrm{N}\left(0, \sigma_{1}\right)$, intended to capture the influence of exogenous events beyond the control;

$\mathrm{u}_{\mathrm{i}}$ is a nonnegative random error term, independently and identically distributed as $\mathrm{N}^{\prime}\left(0, \sigma_{2}\right)$

Now we consider environmentally detrimental inputs.

The inputs of the SFA model are $p_{l j}^{b}$ and $\delta_{j}$, their definitions are

$$
\begin{gathered}
p_{l j}^{b}=y_{l j}^{b} / C o_{l j} \\
\delta_{j}=\sum_{l=1}^{t} \alpha_{l} p_{l j}^{b}
\end{gathered}
$$

where $y_{r j}$ and $y_{l j}^{b}$ are the rth expected and lth unexpected outputs of $\mathrm{jth}, C o_{l j}$ is the environmental capacity of lth unexpected outputs of $\mathrm{jth}, \alpha_{l}$ is the loss coefficient,

$O_{r j}=y_{r j} / \delta_{j}$ refers to the regulated expected output, $O_{r j}=y_{r j} / \delta_{j}, \quad \mathrm{r}=1,2, \ldots \mathrm{s}$ is the adjusted total outputs and $\beta_{j}$ is the risk attitude representing the efficiency of the decision maker.

Now we have

$$
\begin{gathered}
\ln y_{r i}-\ln \delta_{i}=\beta_{0}+\sum_{1}^{k \sum_{i}+i_{i}} \beta_{k} \ln x_{k i}+\ln \\
\delta_{j}=x_{(k+1) j}, \beta_{(k+1)}=1 \\
\ln y_{r i}=\beta_{0}+\sum_{1}^{k+1 \sum_{i}+i_{i}} \beta_{k} \ln x_{k i}+\ln
\end{gathered}
$$

Environmental capacity refers to the maximum contaminant capacity which does not significantly harm the ecological system(Luo, 2012).

We use $r_{i}$ as the environmental capacity of the selected region we want to study. It also obey normal distribution or chi-square distribution(G. King, I. Plosser, \& Rebelo, 2002).

$$
\operatorname{lny}_{i}=\beta_{0}+\sum_{1}^{k+1 \sum_{i i_{i}}} \beta_{k} \ln x_{k i}+\ln
$$

\subsection{Selection of regional ecological efficiency evaluation indicators}

From the data listed in the China Statistical Yearbook, we calculate the local evaluation index of every province in China. Tibet is excluded due to incomplete data statistics. In some years, there is no total industrial exhaust gas emission data, which is replaced by the total amount of smoke (powder) dust emissions. Since the calculation is a region's annual eco-efficiency, there is no cross-year impact. All data used are from the China Statistical Yearbook 2003-2016(China, 2003-2016).

Table 1. Selection of ecological efficiency evaluation indicators

\begin{tabular}{|l|l|l|}
\hline Index & Name & Detailed description \\
\hline \multirow{3}{*}{ Input } & Amount of capital & Fixed capital(0.1 billion Yuan $)$ \\
\cline { 2 - 3 } & Amount of human resources & The labor (ten thousands $)$ \\
\cline { 2 - 3 } & Amount of assumed energy & $100 \mathrm{M} \mathrm{kW} \cdot \mathrm{h}$ \\
\hline $\begin{array}{l}\text { Expected } \\
\text { output }\end{array}$ & Economic output & Local GDP(0.1 billion Yuan $)$ \\
\hline $\begin{array}{l}\text { Unexpected } \\
\text { output }\end{array}$ & & Amount of waste water(ten hundreds ton $)$ \\
\cline { 2 - 3 } & & Amount of waste gas $(0.1$ billion cubic meter $)$ \\
\hline
\end{tabular}

\section{3 evaluation result of local ecological efficiency}

From the data listed in the China Statistical Yearbook, we calculate the local evaluation index of every province 
in China. Tibet is excluded due to incomplete data statistics. In some years, there is no total industrial exhaust gas emission data, which is replaced by the total amount of smoke (powder) dust emissions. Since the calculation is a region's annual eco-efficiency, there is no cross-year impact. All data used are from the China Statistical Yearbook 2003-2016(China, 2003-2016).

The calculation results are listed in the table below.

Table 2. The calculation results of local ecological efficiency

\begin{tabular}{|c|c|c|c|c|c|c|c|}
\hline & 2003 & 2004 & 2005 & 2006 & 2007 & 2008 & 2009 \\
\hline Beijing & 0.4481851 & 0.4954173 & 0.6071799 & 0.6031369 & 0.6144830 & 0.6806032 & 0.6401211 \\
\hline Tianjin & 0.6547441 & 0.8007699 & 0.7760539 & 0.7789601 & 0.8010553 & 0.8329289 & 0.8739967 \\
\hline Hebei & 0.3401713 & 0.3543931 & 0.3611803 & 0.2430798 & 0.3273836 & 0.3599068 & 0.3337259 \\
\hline Shanxi & 0.3504620 & 0.3810005 & 0.4080705 & 0.1705280 & 0.3669328 & 0.3838532 & 0.3689959 \\
\hline Nei Mongol & 0.4471054 & 0.4340108 & 0.5313067 & 0.2837428 & 0.5243722 & 0.5593135 & 0.5491291 \\
\hline Liaoning & 0.3439232 & 0.3687327 & 0.3513648 & 0.2360818 & 0.3697268 & 0.3305128 & 0.3946011 \\
\hline Jilin & 0.5064905 & 0.5511887 & 0.5779920 & 0.3183468 & 0.6138826 & 0.6052004 & 0.6091394 \\
\hline Heilongjiang & 0.5072045 & 0.5796902 & 0.5773094 & 0.2840720 & 0.5147979 & 0.5427942 & 0.4948064 \\
\hline Shanghai & 0.4334701 & 0.4935565 & 0.5479974 & 0.6027889 & 0.5383759 & 0.5332427 & 0.5371739 \\
\hline Jiansu & 0.3100029 & 0.3356848 & 0.3426132 & 0.3212541 & 0.3672658 & 0.3765540 & 0.3830782 \\
\hline Zhejiang & 0.3948517 & 0.4194474 & 0.4148300 & 0.3710101 & 0.3916158 & 0.3706168 & 0.3533597 \\
\hline Anhui & 0.4360134 & 0.4860202 & 0.4945800 & 0.2880155 & 0.4468744 & 0.4455281 & 0.4536905 \\
\hline Fujian & 0.4668048 & 0.4704569 & 0.4502020 & 0.3658211 & 0.4298526 & 0.4257224 & 0.4242645 \\
\hline Jiangxi & 0.4881134 & 0.5404811 & 0.5608223 & 0.3060613 & 0.5242123 & 0.5343699 & 0.5304054 \\
\hline Shandong & 0.3386684 & 0.3668438 & 0.3629842 & 0.2866578 & 0.3535525 & 0.3516810 & 0.3491034 \\
\hline Henan & 0.3126098 & 0.3398903 & 0.3498247 & 0.2081944 & 0.3498267 & 0.3515174 & 0.3416706 \\
\hline Hubei & 0.3484773 & 0.3709641 & 0.3680810 & 0.2597585 & 0.4029066 & 0.4026202 & 0.4081032 \\
\hline Hunan & 0.3638803 & 0.4014957 & 0.4202329 & 0.2238537 & 0.4232108 & 0.4327462 & 0.4237674 \\
\hline Guangdong & 0.2634016 & 0.2899007 & 0.3126512 & 0.3024011 & 0.3169591 & 0.3209709 & 0.3165064 \\
\hline Guangxi & 0.3491200 & 0.3589145 & 0.3729480 & 0.2416380 & 0.3634274 & 0.3611646 & 0.3795375 \\
\hline Hainan & 0.9524520 & 0.9964487 & 0.9907939 & 0.9553034 & 0.9954190 & 0.9593492 & 0.9784249 \\
\hline Chongqing & 0.4646565 & 0.5074940 & 0.5235644 & 0.3372729 & 0.4961558 & 0.5262665 & 0.4851076 \\
\hline Sichuan & 0.3373443 & 0.3742235 & 0.3786302 & 0.2370386 & 0.3402674 & 0.3834045 & 0.3932356 \\
\hline Guizhou & 0.4988735 & 0.5452514 & 0.6166058 & 0.3083357 & 0.4878509 & 0.6443778 & 0.6210713 \\
\hline Yunnan & 0.5322736 & 0.5590896 & 0.5955488 & 0.3740565 & 0.5259864 & 0.5645711 & 0.5166952 \\
\hline Shaanxi & 0.4602171 & 0.5057509 & 0.5407160 & 0.2720856 & 0.5305565 & 0.5152907 & 0.5060612 \\
\hline Gansu & 0.5854470 & 0.6841674 & 0.6799426 & 0.3707109 & 0.6360880 & 0.6546783 & 0.6825792 \\
\hline Qinghai & 0.9856687 & 0.9732032 & 0.9755061 & 0.9899182 & 0.9621627 & 0.9760146 & 0.9728759 \\
\hline Ningxia & 0.6537416 & 0.6727847 & 0.6706504 & 0.4574878 & 0.7181004 & 0.7883163 & 0.8032753 \\
\hline Xinjiang & 0.5473160 & 0.5840970 & 0.5975647 & 0.3103107 & 0.5714207 & 0.5808265 & 0.5704460 \\
\hline
\end{tabular}




\begin{tabular}{|c|c|c|c|c|c|c|c|}
\hline & 2010 & 2011 & 2012 & 2013 & 2014 & 2015 & 2016 \\
\hline Beijing & 0.6417642 & 0.6531069 & 0.7541431 & 0.9149307 & 0.8296898 & 0.7252711 & 0.7589733 \\
\hline Tianjin & 0.7814954 & 0.6909507 & 0.6789032 & 0.8671803 & 0.7562392 & 0.6837094 & 0.7748075 \\
\hline Hebei & 0.3067170 & 0.2727536 & 0.2794444 & 0.3185844 & 0.2870340 & 0.1991098 & 0.2292756 \\
\hline Shanxi & 0.3139510 & 0.3004042 & 0.3443741 & 0.3946492 & 0.3702602 & 0.1842354 & 0.2768133 \\
\hline Nei Mongol & 0.5044687 & 0.4915259 & 0.5229006 & 0.5728774 & 0.4872829 & 0.3122898 & 0.3773137 \\
\hline Liaoning & 0.3819343 & 0.3515755 & 0.3648117 & 0.4395278 & 0.3672360 & 0.2651626 & 0.3339398 \\
\hline Jilin & 0.5764215 & 0.5500565 & 0.5897822 & 0.7520957 & 0.6716793 & 0.4056204 & 0.5678384 \\
\hline Heilongjiang & 0.5032531 & 0.4875700 & 0.5058963 & 0.6351338 & 0.5530856 & 0.3096839 & 0.3672020 \\
\hline Shanghai & 0.4783291 & 0.4941208 & 0.5616891 & 0.6862169 & 0.6327447 & 0.5501573 & 0.5966957 \\
\hline Jiansu & 0.3524482 & 0.3157944 & 0.3276320 & 0.3400925 & 0.3005621 & 0.2619756 & 0.2981941 \\
\hline Zhejiang & 0.3333036 & 0.3260972 & 0.3727623 & 0.4552090 & 0.4055155 & 0.3394506 & 0.3877070 \\
\hline Anhui & 0.4254377 & 0.3467439 & 0.3731608 & 0.4587991 & 0.4059777 & 0.2993870 & 0.3767023 \\
\hline Fujian & 0.3932713 & 0.3555127 & 0.4287553 & 0.5118058 & 0.4457913 & 0.3387588 & 0.3963468 \\
\hline Jiangxi & 0.4966026 & 0.4158080 & 0.4770290 & 0.5875184 & 0.5478671 & 0.3395279 & 0.3861419 \\
\hline Shandong & 0.3047192 & 0.2840090 & 0.2938743 & 0.3387625 & 0.2946428 & 0.2237829 & 0.2562110 \\
\hline Henan & 0.3229587 & 0.2687497 & 0.2823854 & 0.3147893 & 0.2767586 & 0.2097189 & 0.2737797 \\
\hline Hubei & 0.3900179 & 0.3372231 & 0.3833929 & 0.4644424 & 0.4044834 & 0.3196340 & 0.3934400 \\
\hline Hunan & 0.3914635 & 0.3760428 & 0.3928500 & 0.4717469 & 0.4358366 & 0.3372926 & 0.4159659 \\
\hline Guangdong & 0.2923190 & 0.1454558 & 0.3005189 & 0.3582235 & 0.3108057 & 0.2189057 & 0.2834179 \\
\hline Guangxi & 0.3631001 & 0.3414642 & 0.3533849 & 0.4593002 & 0.4282728 & 0.3408629 & 0.4030907 \\
\hline Hainan & 0.9530852 & 0.9850138 & 0.9666136 & 0.9833183 & 0.9830935 & 0.9825937 & 0.9562796 \\
\hline Chongqing & 0.4999147 & 0.4978723 & 0.5815277 & 0.6917279 & 0.6224802 & 0.4729544 & 0.5442778 \\
\hline Sichuan & 0.3620418 & 0.3442544 & 0.3896750 & 0.4848928 & 0.4284747 & 0.3214764 & 0.3666093 \\
\hline Guizhou & 0.5738526 & 0.5437887 & 0.5270854 & 0.5223386 & 0.4670348 & 0.3775688 & 0.4488717 \\
\hline Yunnan & 0.4710401 & 0.3731459 & 0.4065183 & 0.4854036 & 0.4237257 & 0.3303215 & 0.3652472 \\
\hline Shaanxi & 0.4686056 & 0.1823431 & 0.4769874 & 0.5464730 & 0.4805249 & 0.2893349 & 0.3806060 \\
\hline Gansu & 0.6982809 & 0.5494128 & 0.5883489 & 0.7281180 & 0.6487596 & 0.3984338 & 0.4905297 \\
\hline Qinghai & 0.9310086 & 0.2995270 & 0.8440800 & 0.9796880 & 0.8914924 & 0.4804231 & 0.6128669 \\
\hline Ningxia & 0.5315265 & 0.6607165 & 0.6856841 & 0.8322059 & 0.7043213 & 0.4954588 & 0.5557223 \\
\hline Xinjiang & 0.5389264 & 0.5017647 & 0.4581467 & 0.4996854 & 0.4151450 & 0.2611565 & 0.2976669 \\
\hline
\end{tabular}

4. Training and examining of the hybrid SFA-Artificial Neural Network (SFANN) model used to evaluate the performance of ecological civilization policy

\subsection{Construction of the model and selection of an evaluating index}

Now we have obtained the regional annual eco-efficiency value above, but the evaluation result is static. Since the implementation of the ecological civilization policy has multiple effects on the economy and has a time accumulation effect, we use a multiple neural network with hidden layers in order to evaluate and predict the dynamic and cumulative efficiency of the ecological civilization policy.

The output layer node is the final output value, so the number of output layer nodes is 1 where the regional Gross Domestic Product (GDP) is used. The input layer node (ecological civilization policy) includes two parts: the production input policy and the reduction of major pollutants emissions policy. The production input policy stipulates the fixed capital input (total investment in fixed assets )and total wage bills of employed persons. Reduction of the major pollutants emission policy includes the allowed total amount of COD, ammonia nitrogen and $\mathrm{SO} 2$, taking into account the factor of DEA eco-efficiency evaluation and the region serial number; 
therefore, the number of input layer nodes is 7 .

We select a neural network with two hidden layers, and the number of nodes is determined by the following empirical formula:

$$
H=\sqrt{N+O}+\alpha, 1<\alpha<10
$$

where $\mathrm{N}$ is the number of input layer nodes and $\mathrm{O}$ is the number of output layer nodes.

We then normalize the input data of the neural network, and the normalization function is as follows:

$$
u(z)=\frac{z-z_{\min }}{z \min _{\max }}
$$

where $\mathrm{z}$ is the input (output) sample, and zmin and zmax are the minimum and maximum values of the input (output) sample, respectively. That is to say, the data are normalized in the [0,1] interval.

The training parameters of the Neural Network are as follows:

Training function: Gradient Descent Optimizer

Activation function: $\mathrm{f}(\mathrm{x})=\max (\mathrm{x}, 0)($ relu $)$

Learning rate: 0.03

Maximum number of iterations: 24000

Transfer function: linear transfer function (purelin)

After repeated training and adjustment, the number of nodes of the two hidden layers are: 11,7.

\subsection{Training and examination of the hybrid model}

Since there is retardation of the impact of policies on the economy, when the model is trained and examined, the data are used in the following way: using the evaluation results of the regional eco-efficiency of the previous year to match the total investment in fixed assets, the total wage bills of employed persons, COD, ammonia nitrogen and SO2 of the year. The data from 2003-2013 are used as the trained set, the data from 2014-2016 are used as the examined set. All the data come from the 2003-2016 China Statistical Yearbook, and normalization processing is applied to the data(China, 2003-2016).

Substituting the data into the model, the prediction and error of the examined set are as follows(Table 4).

Table 3. The comparison of prediction and actual value

\begin{tabular}{|l|r|r|r|l|r|r|}
\hline $\begin{array}{l}\text { (Billion } \\
\text { Yuan) }\end{array}$ & $\begin{array}{l}\text { Prediction of } \\
\text { 2014 }\end{array}$ & $\begin{array}{l}\text { Actual of } \\
2014\end{array}$ & $\begin{array}{l}\text { Prediction of } \\
2015\end{array}$ & $\begin{array}{l}\text { Actual of } \\
2015\end{array}$ & $\begin{array}{l}\text { Prediction } \\
\text { of } 2016\end{array}$ & \multicolumn{1}{l}{$\begin{array}{l}\text { Actual of } \\
2016\end{array}$} \\
\hline Beijing & 18887.9126 & 21330.83036 & 18712.70006 & 23014.59013 & 23544.23 & 25669.13 \\
\hline Tianjin & 17188.77801 & 15726.93031 & 17061.03645 & 16538.18991 & 13644.02 & 17885.39 \\
\hline Hebei & 31588.1589 & 29421.15 & 33176.86107 & 29806.10998 & 33156.51 & 32070.45 \\
\hline Shanxi & 16761.26866 & 12761.48986 & 18780.1518 & 12766.49024 & 12030.84 & 13050.41 \\
\hline Nei Mongol & 24758.79016 & 17770.1903 & 15694.22408 & 17831.50972 & 17681.77 & 18128.1 \\
\hline Liaoning & 26961.15015 & 28626.57978 & 29283.27672 & 28669.02024 & 14566.29 & 22246.9 \\
\hline Jilin & 14569.47578 & 13803.14028 & 14840.1562 & 14063.13022 & 14143.37 & 14776.8 \\
\hline Heilongjiang & 20465.38121 & 15039.3798 & 19463.51476 & 15083.67025 & 14286.38 & 15386.09 \\
\hline Shanghai & 26305.52939 & 23567.70013 & 31813.18174 & 25123.44971 & 25736.67 & 28178.65 \\
\hline Jiansu & 60625.65887 & 65088.31966 & 68813.96007 & 70116.38027 & 71287.02 & 77388.28 \\
\hline Zhejiang & 37890.71381 & 40173.02963 & 49056.26089 & 42886.49009 & 43785.4 & 47251.36 \\
\hline Anhui & 24979.03296 & 20848.75004 & 22154.10447 & 22005.62967 & 28114.34 & 24407.62 \\
\hline Fujian & 21505.38417 & 24055.76014 & 29924.90158 & 25979.81975 & 26234.51 & 28810.58 \\
\hline Jiangxi & 19795.50291 & 15714.62973 & 21676.42641 & 16723.7801 & 19623.1 & 18499 \\
\hline Shandong & 63182.84944 & 59426.59015 & 63333.14042 & 63002.33033 & 62964 & 68024.49 \\
\hline Henan & 36646.45653 & 34938.24028 & 46481.1213 & 37002.16002 & 45440.76 & 40471.79 \\
\hline Hubei & 32443.06764 & 27379.22017 & 32554.43604 & 29550.1902 & 31215.39 & 32665.38 \\
\hline
\end{tabular}




\begin{tabular}{|l|r|r|r|r|r|r|} 
Hunan & 24602.68914 & 27037.32026 & 32113.17321 & 28902.20979 & 30522.24 & 31551.37 \\
\hline Guangdong & 62907.72371 & 67809.8496 & 75667.61259 & 72812.55023 & 64434.82 & 80854.91 \\
\hline Guangxi & 14667.35941 & 15672.89017 & 19130.6597 & 16803.11988 & 16649.02 & 18317.64 \\
\hline Hainan & 1458.840687 & 3500.720207 & 1359.200858 & 3702.759985 & 3602.8 & 4053.2 \\
\hline Chongqing & 14737.34787 & 14262.59979 & 18397.31039 & 15717.26994 & 16077.03 & 17740.59 \\
\hline Sichuan & 35558.5254 & 28536.65987 & 34288.07679 & 30053.10006 & 29795.54 & 32934.54 \\
\hline Guizhou & 14937.06366 & 9266.389843 & 14132.68471 & 10502.56016 & 13177.65 & 11776.73 \\
\hline Yunnan & 15030.30574 & 12814.59012 & 16611.14162 & 13619.16994 & 15877.73 & 14788.42 \\
\hline Shaanxi & 22669.75545 & 17689.9396 & 19718.91112 & 18021.85968 & 18163.31 & 19399.59 \\
\hline Gansu & 6611.619107 & 6836.820398 & 5611.894253 & 6790.320252 & 9065.593 & 7200.37 \\
\hline Qinghai & 3652.197244 & 2303.320131 & 2743.899195 & 2417.050188 & 2538.641 & 2572.49 \\
\hline Ningxia & 2741.203328 & 2752.099727 & 3487.383481 & 2911.769862 & 2311.831 & 3168.59 \\
\hline Xinjiang & 12930.33093 & 9273.4599 & 9854.21226 & 9324.80029 & 10082.66 & 9649.7 \\
\hline
\end{tabular}

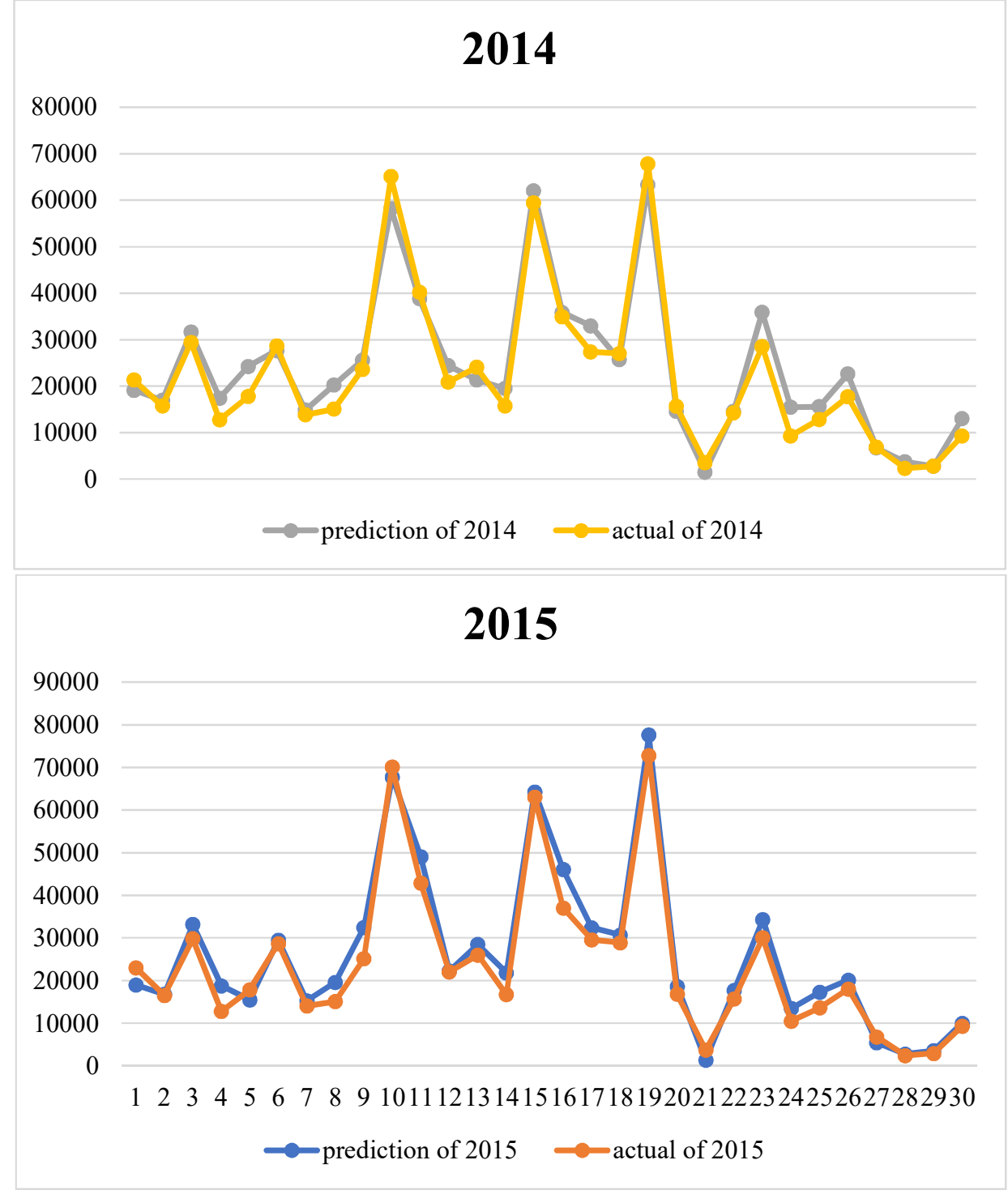




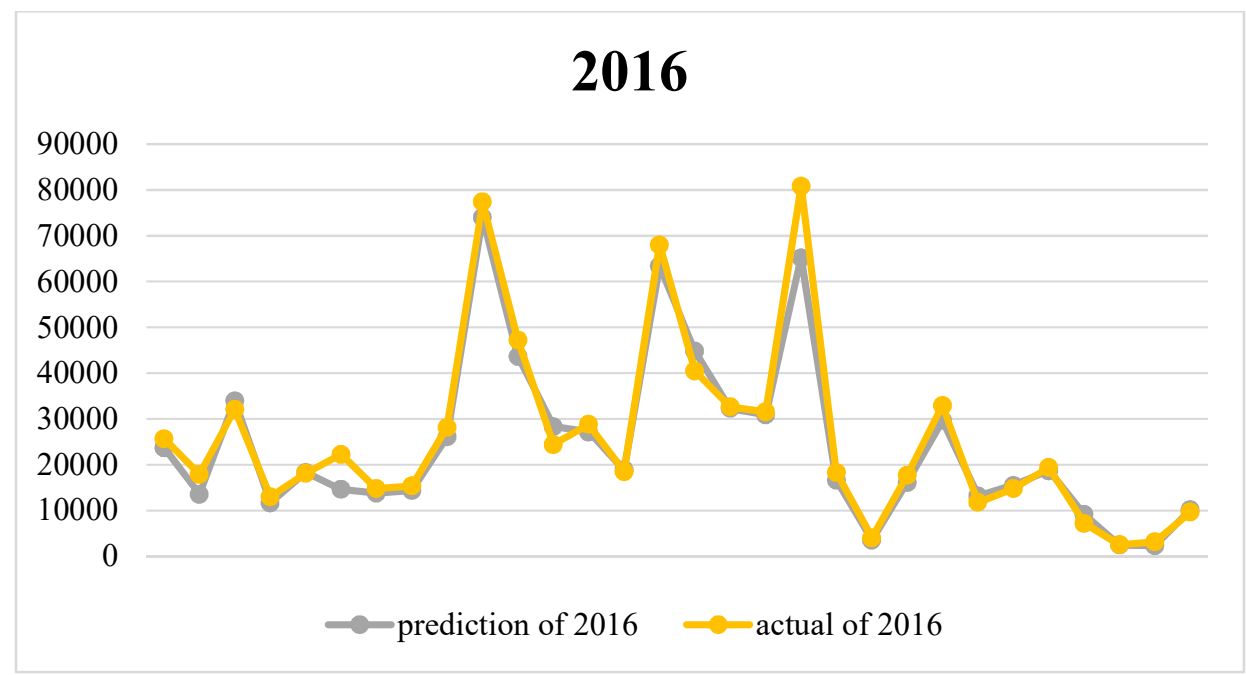

Figure 4. The comparison of prediction and actual value

It can be seen from the Figure 4 that the SFANN model has good accuracy in predicting policy performance. Some large errors, such as the error for Northern China in 2014, may be due to severe winter smog. Since there are emergency plans in ecological civilization policies, the predicted results are generally higher than the actual value. Most of the predictions are accurate if the policy remains stable and continuous to some degree.

\section{Prediction of the economic impact of the Total Emission Reduction Policy by using the SFANN model on a five-year plan (2016-2020)'s data}

The trained SFANN model system can help us predict the impact of ecological civilization policies on the economy, help us assess whether policies are feasible and can help in achieving established policy goals.

In the following case, we try to predict the supposed emission and energy consumption data from the set goal of saving energy and cutting emissions, which was issued in the five-year plan (2016-2020) by the State Council of China on Jan 5, 2017(Council, 2016). Additionally, we assume that the increase in total wages is the same as the rate of GDP growth. The data of Xinjiang Province is the sum of Xinjiang and China Xinjiang Production and Construction Corps in the five-year plan.

We adjust different input values, the fixed asset investment, of the trained SFANN model system until the output value, the predicted economic growth rate, is greater than the lowest set economic growth rate. The final fixed asset investment growth is shown in the next table(Table 4).

We can treat this as the basis for measuring whether a policy is feasible. If we cannot afford a high production input, then we have to reduce environmental requirements and allow more emissions. Otherwise, if we want to maintain economic growth and protect the environment, we must increase investment. Additionally, the efficiency improvement caused by technological transformation accumulates growth year by year2.

Table 4. The target of economic growth

\begin{tabular}{|c|c|c|c|c|c|}
\hline & $\begin{array}{l}\text { Lower limit of } \\
\text { GDP(Billion) }\end{array}$ & $\begin{array}{l}\text { Lower limit of Total } \\
\text { wage(Billion) }\end{array}$ & $\begin{array}{l}\text { Upper limit of } \\
\text { COD(Ten thousand } \\
\text { tons) }\end{array}$ & $\begin{array}{l}\text { Upper limit of Ammonia } \\
\text { nitrogen (Ten thousand } \\
\text { tons) }\end{array}$ & $\begin{array}{l}\text { Upper limit of } \\
\mathrm{SO}_{2} \text { (Ten thousand } \\
\text { tons) }\end{array}$ \\
\hline Beijing & 31531.98282 & 10532.68 & 13.8244 & 1.38435 & 4.628 \\
\hline Tianjin & 22658.75356 & 2951.17 & 17.89896 & 1.99682 & 13.9425 \\
\hline Hebei & 40836.9538 & 4062.99 & 97.8561 & 7.784 & 79.8048 \\
\hline Shanxi & 17491.19769 & 3042.83 & 33.38024 & 4.1082 & 89.648 \\
\hline Nei Mongol & 24430.71404 & 2291.2 & 77.62724 & 4.3617 & 109.5501 \\
\hline Liaoning & 39279.04196 & 4494.16 & 101.1055 & 8.78256 & 77.504 \\
\hline
\end{tabular}




\begin{tabular}{|c|c|c|c|c|c|}
\hline Jilin & 19267.70686 & 2178.3 & 68.94384 & 4.81104 & 29.7578 \\
\hline Heilongjiang & 20665.9351 & 2785.52 & 130.9138 & 7.5609 & 40.6107 \\
\hline Shanghai & 34421.30378 & 8975.85 & 16.9974 & 3.6805 & 13.664 \\
\hline Jiansu & 96065.51712 & 13086.52 & 91.2229 & 11.92482 & 66.808 \\
\hline Zhejiang & 58758.20799 & 9134.09 & 55.20256 & 8.1164 & 44.6374 \\
\hline Anhui & 30149.62018 & 3605.52 & 78.48611 & 8.29576 & 40.3284 \\
\hline Fujian & 35594.6049 & 4739.13 & 58.44146 & 8.21215 & 33.79 \\
\hline Jiangxi & 22913.02794 & 2902.25 & 68.48292 & 8.13852 & 46.4728 \\
\hline Shandong & 86318.6521 & 8967.77 & 155.19608 & 13.18052 & 111.3761 \\
\hline Henan & 50696.16593 & 6294.45 & 105.03552 & 11.20062 & 82.3896 \\
\hline Hubei & 40486.32122 & 4755.98 & 88.84761 & 10.26414 & 44.112 \\
\hline Hunan & 39598.53246 & 3836.38 & 108.57223 & 13.58389 & 47.0445 \\
\hline Guangdong & 99759.50368 & 16118.8 & 143.97824 & & 65.7951 \\
\hline Guangxi & 23021.73062 & 2466.7 & 70.4088 & 7.5933 & 36.6444 \\
\hline Hainan & 5073.102094 & 688.88 & 18.56452 & 2.0601 & 3.23 \\
\hline Chongqing & 21534.02201 & 3094.48 & 35.16948 & 4.69437 & 40.6556 \\
\hline Sichuan & 41175.3515 & 5813.28 & 103.45408 & 11.31354 & 60.2784 \\
\hline Guizhou & 14389.41739 & 2177.89 & 29.12445 & 3.23232 & 79.329 \\
\hline Yunnan & 18659.44318 & 2615.91 & 43.83477 & 4.78179 & 57.7863 \\
\hline Shaanxi & 24691.51004 & 3647.72 & 44.019 & 5.004 & 62.475 \\
\hline Gansu & 9303.326872 & 17089.09 & 33.57126 & 3.4224 & 52.4952 \\
\hline Qinghai & 3311.56797 & 490.9 & 10.31527 & 0.986 & 14.1752 \\
\hline Ningxia & 3989.377244 & 581.33 & 20.8468 & 1.60866 & 31.4688 \\
\hline Xinjiang & 12775.78412 & 2555.35 & 64.97352 & 4.43232 & 74.39467584 \\
\hline
\end{tabular}

From the data in the Table 5 we can see the following trend: In key areas, especially those suffering from heavy pollution, when emissions are heavily cut, those provinces have to input(invest) more than others to achieve the same economic growth rate. The increased investment can be invested in low emission industries, or in transforming the technology of existing production capacity to cut emissions. In contrast, in the 'greener ' areas, the investment growth needs less input. Such a nonlinear relationship is well expressed by the SFANN model. 
Table 5. The prediction of fixed asset investment growth rate, which can suit 2020's economic growth target

\begin{tabular}{|c|c|}
\hline & $\begin{array}{l}\text { Fixed asset investment } \\
\text { growth rate in } 2020(\%)\end{array}$ \\
\hline Beijing & 28.32466431 \\
\hline Tianjin & 37.78462552 \\
\hline Hebei & 27.91036208 \\
\hline Shanxi & 16.24425275 \\
\hline Nei Mongol & 24.21763524 \\
\hline Liaoning & 48.83809452 \\
\hline Jilin & 20.01606723 \\
\hline Heilongjiang & 19.77744736 \\
\hline Shanghai & 26.66693875 \\
\hline Jiansu & 7.160918072 \\
\hline Zhejiang & 38.24451596 \\
\hline Anhui & 15.06136148 \\
\hline Fujian & 9.207697159 \\
\hline Jiangxi & 4.650525687 \\
\hline Shandong & 58.32698191 \\
\hline Henan & 24.25488431 \\
\hline Hubei & 23.3531327 \\
\hline Hunan & 25.98054552 \\
\hline Guangdong & 63.5407064 \\
\hline Guangxi & 10.17626221 \\
\hline Hainan & 20.85351803 \\
\hline Chongqing & 15.31349729 \\
\hline Sichuan & 18.19825216 \\
\hline Guizhou & 15.0595301 \\
\hline Yunnan & 9.633360071 \\
\hline Shaanxi & 15.52037702 \\
\hline Gansu & 7.601759223 \\
\hline Qinghai & 7.327958411 \\
\hline Ningxia & 15.16193598 \\
\hline Xinjiang & 5.513145586 \\
\hline
\end{tabular}

\section{Conclusions and Policy Implications}

This paper proposes the SFANN model, which is used to evaluate the performance of ecological civilization policy on the basis of regional eco-efficiency evaluation. By training and examining the evaluation results, this paper provides a quantitative evaluation of the ecological civilization policy in different provincial regions from 2003-2016 and tries to predict the performance of emissions reduction policy in environmental planning in the 13th Five-Year Plan.

Based on the study's results, we can draw the following conclusions. (1) Development and the environment can achieve a win-win situation. We cannot obtain economic development at the expense of environmental pollution, and we cannot pursue environmental protection at the risk of economic stagnation. In addition to protecting the environment, the ecological civilization policy has a huge impact on economic development. We can achieve a dynamic balance between economic development and environmental protection by controlling the input of 
ecological civilization policies. (2) Regional eco-efficiency differs based on not only on the input of ecological civilization policy but also on the local environmental capacity and risk attitude. Therefore, when the ecological civilization policy is evaluated, a different method should be used the main functions and positions of different areas. (3) The performance of ecological civilization policy in the regions of different eco-efficiencies can be regulated through different policies. In developed areas with high ecological efficiency, although current environmental problems are prominent, , it will not be difficult to achieve the goal of environmental quality improvement due to a good foundation. Less-developed areas with low ecological efficiency need to make a great effort to improve the quality of ecological environment. Developing areas with high ecological efficiency require a large number of policies for support, in order to protect their fragile ecological environment and develop their economy at the same time; developed areas with low ecological efficiency need precise control of policies because of their large development base. It is necessary to avoid both over-regulation and a lack of regulation.

Because of the Artificial Neural Network's special negative feedback mechanisms, we suggest eight ways to improve the performance of ecological civilization from the evaluation result: (1) boost the legislation regarding ecological civilization, (2) complete an organizational decision-making mechanism of ecological civilization, (3) establish an economic policy system for ecological civilization, (4) strengthen the adjustment mechanics of interests, (5) set up public participation mechanisms, (6) construct a supervision mechanism for ecological civilization policy, (7) improve the performance evaluation mechanics of ecological civilization policy, and (8) deepen the structural reform of the supply-side for supporting systems.

\section{References}

Aibao, H. (2010). A Review on Government Environment Performance Appraisal. JIANGSU SOCIAL SCIENCES(3), 244-249.

Battese, G., \& J. Coelli, T. (1988). Prediction of firm-level technical efficiencies with a generalized frontier production function and panel data. Journal of Econometrics, 38(3), 387-399.

Cao, Y., \& Cao, D. (2010). Environmental Performance Assessment in the Environmental Strategy Implementation. Ecological Economy.

China, N. b. o. s. o. (2003-2016). Statistics Yearbook of China: China Statistics Press.

China, N. B. o. S. o. (2017). Green development index calculation method. Beijing, China: China Statistics Press.

Council, G. O. o. t. S. (2016). Saving energy and Cutting emissions. In G. O. o. t. S. C. o. t. P. s. R. o. China (Ed.). Beijing,China.

G. King, R., I. Plosser, C., \& Rebelo, S. (2002). Production, Growth and Business Cycles: Technical Appendix. Computational Economics, 20(1-2), 87-116.

Gass, S., \& Vargas, L. G. (2017). The Analytic Hierarchy Process: John Wiley \& Sons, Ltd.

Ji-Hong, L. I. (2007). Rachel Carsen and Her Silent Spring. Chinese Journal of Nature.

Li-Yang, S. U., Zheng, H. X., \& Wang, Y. (2013). Evaluation on Green Development of China's Provincial Industry. China Population Resources \& Environment.

Liu, Y. J. (2010). Construction of Evaluation System of Provincial Ecological Civilization. Journal of Anhui Agricultural Sciences.

Luo, Y. (2012). DEA-based Research on Indicator Selection and Environmental Performance Measurement. University of Science and Technology of China.

Maxim, L., Spangenberg, J. H., \& O'Connor, M. (2009). An analysis of risks for biodiversity under the DPSIR framework. Ecological Economics, 69(1), 12-23.

OECD. (1998). Eco-efficiency. Paris: Organization for Economic Cooperation and Development.

Reinhard, S., Knox Lovell, C. A., \& Thijssen, G. J. (2000). Environmental efficiency with multiple environmentally detrimental variables; estimated with SFA and DEA. European Journal of Operational Research, 121(2), 287-303.

Sc, C., Cowan, C. F. N., \& Grant, P. M. (1991). Orthogonal Least Squares Learning Algorithm for Radial Basis 
Function Networks. IEEE Transactions on Neural Networks. 2(2): 302-309. IEEE Transactions on Neural Networks, 2(2), 302-309.

van den Bergh, J. C. J. M., \& Verbruggen, H. (1999). Spatial sustainability, trade and indicators: an evaluation of the 'ecological footprint'. Ecological Economics, 29(1), 61-72.

Vörösmarty, C. J., McIntyre, P. B., Gessner, M. O., Dudgeon, D., Prusevich, A., Green, P., et al. (2010). Global threats to human water security and river biodiversity. Nature, 468, 334.

WBCSD. (1996). Eco-efficiency:Leadership for Improved Economic and Environmental Performance (Vol. 1). Geneva: WBCSD.

Xiao, Z., Ye, S.-J., Zhong, B., \& Sun, C.-X. (2009). BP neural network with rough set for short term load forecasting. Expert Systems with Applications, 36(1), 273-279.

Zhang, X., Li, Y., Shi, H., \& Yang, Z. (2015). To Design the Institutional System for Ecological Civilization. Chinese Journal of Environmental Management.

Zhang, X., \& Yue, Y. (2017). Get through the Last Kilometer between Legislation and Public Opinion-An Empirical Research to Resolve the Predicament of Public Participation Orderly in Local Legislation. Chinese Public Administration.

Zhang, Y., \& Wu, L. (2009). Stock market prediction of S\&P 500 via combination of improved BCO approach and BP neural network. Expert Syst. Appl., 36(5), 8849-8854. 